\title{
Increasing Hepatitis C treatment uptake among HIV-infected patients using an HIV primary care model
}

\author{
Edward R Cachay ${ }^{1,3^{*}}$, Lucas Hill2, Craig Ballard ${ }^{2}$, Bradford Colwell ${ }^{2}$, Francesca Torriani ${ }^{1,3}$, David Wyles ${ }^{1,3}$ and
} William C Mathews'

\begin{abstract}
Background: Access to Hepatitis C (HCV) care is low among HIV-infected individuals, highlighting the need for new models to deliver care for this population.

Methods: Retrospective cohort analysis that compared the number of HIV patients who initiated HCV therapy: hepatology (2005-2008) vs. HIV primary care model (2008-2011). Logistic-regression modeling was used to ascertain factors associated with HCV therapy initiation and achievement of sustained viral response (SVR).

Results: Of 196 and 163 patients that were enrolled in the HIV primary care and hepatology models, 48 and 26 were treated for $\mathrm{HCV}$, respectively $(p=0.043)$. The HIV/HCV-patient referral rate did not differ during the two study periods ( 0.10 vs. 0.12 /patient-yr, $p=0.18)$. In unadjusted analysis, predictors $(p<0.05)$ of HCV treatment initiation included referral to the HIV primary care model (OR: 1.7), a CD4+ count $\geq 400 / \mathrm{mm} 3$ (OR: 1.8) and alanine aminotranferase level $\geq 63 \mathrm{U} / \mathrm{L}$ (OR: 1.9). Prior psychiatric medication use correlated negatively with HCV treatment initiation (OR: $0.6, p=0.045)$. In adjusted analysis the strongest predictor of HCV treatment initiation was CD4+ count ( $\geq 400 / \mathrm{mm} 3$, OR: $2.1, p=0.01)$. There was no significant difference in either clinic model (primary care vs. hepatology) in the rates of treatment discontinuation due to adverse events ( $29 \%$ vs. $16 \%$ ), loss to follow-up (8 vs. $8 \%)$, or HCV SVR (44 vs. 35\%).
\end{abstract}

Conclusions: Using a HIV primary care model increased the number of HIV patients who initiate HCV therapy with comparable outcomes to a hepatology model.

Keywords: HIV, HCV treatment, Primary care, Hepatology

\section{Introduction}

Access to hepatitis $\mathrm{C}(\mathrm{HCV})$ treatment remains low in HIV-infected individuals in the USA [1-3], resulting in increased morbidity and cost due to HCV related complications $[4,5]$.

The following factors account in part for the low treatment rates of $\mathrm{HCV}$ in the HIV population: increased prevalence of competing medical co-morbidities [6], ongoing substance/alcohol dependence and neuropsychiatric disease [7]. Additional disincentives for patients to

\footnotetext{
* Correspondence: ecachay@ucsd.edu

'Department of Medicine, Owen Clinic, University of California at San Diego, 200 W. Arbor Drive, San Diego, CA 92103-8681, USA

${ }^{3}$ Department of Medicine, Division of Infectious Diseases, University of California at San Diego, San Diego, CA, USA

Full list of author information is available at the end of the article
}

seek $\mathrm{HCV}$ treatment include: low efficacy and severe side effects associated with conventional HCV therapies (pegylated interferon and ribavirin) [8]; long waiting time prior to $\mathrm{HCV}$ intake appointment in sub-specialty clinics [9]; and commuting to a different location from where they routinely receive their HIV care $[10,11]$.

In April 2008, the University of California at San Diego (UCSD) transitioned from a hepatology specialty model to an HIV primary care hepatitis program for the management of $\mathrm{HCV}$ in HIV-infected patients without advanced cirrhosis. Many centers around the country with a high burden of $\mathrm{HIV} / \mathrm{HCV}$ co-infection have implemented similar multidisciplinary co-infection programs, but there is little data describing the structure, processes, and outcomes of these programs. Thus, we sought to compare 
the rates of referral, treatment initiation and completion between a prior hepatology-managed co-infection clinic and a subsequent HIV primary care managed co-infection clinic after the first three years of transition.

\section{Methods}

Study design and patients

We compared two adult cohorts: (1) UCSD hepatology specialty model (1 Jan 2005-31 March 2008) and (2) the UCSD Owen hepatitis co-infection clinic (1 April 2008-30 July 2011). Inclusion criteria required: (1) a documented clinical decision regarding HCV treatment eligibility; (2) if treated, $\mathrm{HCV}$ treatment consisting of pegylated interferon and ribavirin. The study was approved by the UCSD Human Research Protection Program.

\section{Description of HIV primary care model}

The UCSD Owen clinic cares for more than 3,000 HIVinfected patients of whom approximately $20 \%$ are coinfected with HCV. Prior to April 2008 a team of hepatologists managed a once weekly clinic for assessment of HIV/HCV patients. There were no explicit inclusion criteria for referral to the traditional hepatology-based clinic. Historically, HIV providers made referral decisions based on their own referral criteria. The new hepatitis coinfection primary care model also operates as one clinic session per week and is staffed by three HIV clinicians with Infectious Diseases certification, a psychiatrist, two clinical pharmacists specialized in HIV care, one health educator and a substance counselor. There was no change in procedures for patient referral to the primary care managed co-infection clinic nor were there any other structural changes to the HIV clinic during the transition process; all HIV patients under care with viral hepatitis co-infection could be referred by their HIV primary care provider for evaluation. Every patient underwent a detailed clinical, laboratory and imaging (ultrasound and/or abdomino-pelvic computer tomography) assessment for staging degree of liver disease according to standard of care and ruling out indirect evidence of advanced liver disease and/or portal hypertension [12]. Patients with $\mathrm{HCV}$ genotype 1 or 4 were offered a liver biopsy performed by the interventional radiology service unless patients declined the procedure. Esophagogastroduodenoscopies when required were completed by the gastroenterology service. Our minimal requirements for $\mathrm{HCV}$ treatment eligibility were: (1) undetectable HIV viral load and CD4 cell count $\geq 200 / \mathrm{cm}^{3}$ if on antiretroviral therapy; (2) CD4 cell count $\geq 500 / \mathrm{cm}^{3}$ irrespective of HIV viral load value if naïve to antiretroviral therapy; (3) absence of Child B or C liver cirrhosis; (4) stable concurrent medical co-morbidity; (5) favorable recommendation from the team's psychiatrist; (6) registration in the San Diego needle exchange program in the case of ongoing parenteral drug use with documentation of controlled HIV infection as in (1) and (2), plus documentation of no missed clinic appointments during HCV staging process; and (7) alcohol sobriety for at least 3 months prior to $\mathrm{HCV}$ treatment initiation. Homeless patients were required to receive all weekly pegylated interferon injections in clinic.

\section{HCV treatment monitoring strategies and role of pharmacists in the HIV primary care model}

Following favorable consideration to initiate HCV therapy, a patient was assigned to one of three groups for $\mathrm{HCV}$ treatment monitoring: Group 1 had patients without major significant medical co-morbidity, social barriers and no on-going illicit substance use. Group 2 comprised patients with on-going substance use and/or homelessness, Group 3 included patients with severe neuropsychiatric disease (i.e. prior suicidal attempts) and/or medical co-morbidities (i.e. history of congestive heart failure). Patients were followed by physicians and pharmacist specialized in HIV where frequency of follow-up and laboratory testing was based on monitoring group assignment (Additional file 1: Table S1 and Additional file 2: Table S2). Pharmacists verified: (1) potential medication interactions; (2) HIV antiretroviral adherence; (3) HCV health education; (4) insurance coverage for access to $\mathrm{HCV}$ medication; and (5) patient understanding of HCV medication dosing, administration, and possible side effects. During HCV treatment, HIV pharmacists assist in monitoring: (1) adherence to HCV therapy; (2) critical laboratory results; (3) HCV medication and adjunctive therapy access during treatment course; and (4) unexpected medication interactions/clinical complaints not reported by the patient to physicians.

\section{Study outcomes}

The primary outcome was the difference in the number of referred patients who initiated HCV therapy in both cohorts during the study period. Secondary outcomes were: (1) referral rates by HIV primary care providers for $\mathrm{HCV}$ treatment consideration and (2) proportion of patients that following HCV therapy achieved sustained viral response (SVR).

\section{Independent variables}

The following independent variables were assessed: (1) sociodemographic (age, sex, race/ethnicity, HIV risk factor); (2) HIV related (CD4 cell count, HIV viral load and proportion of patients on antiretroviral therapy); (3) $\mathrm{HCV}$ viral load and genotype; (4) histological severity of liver disease according to modified Knodell score; (5) neuropsychiatric history, including proportion of patients on any psychotropic medications; (6) history of self-reported illicit substance and/or alcohol use within the last 3 months of $\mathrm{HCV}$ treatment evaluation by completion of 
the ASSIST instrument [13] and subsequent evaluation by the substance abuse counselor and (7) laboratory values [hemoglobin, platelet count, alanine aminotransferase (ALT), international normalized ratio (INR)].

\section{Statistics}

Baseline comparison of clinical characteristics between patients referred to the two clinic models was evaluated using exact Wilcoxon tests for continuous and Fisher's test for categorical variables. Among patients referred to each clinic model differences in reasons for deferring HCV therapy were explored using chi-square analyses. Bivariate analyses were used to explore the effect of each independent variable in predicting the decision for $\mathrm{HCV}$ treatment initiation. Then, we fitted a multiple logistic regression model to adjust for confounding and effect modification of variables associated with HCV therapy initiation using the co-variates found to be significant in prior bivariate analysis $(\mathrm{p}<0.10)$. We estimated referral rates as the number of referrals per patient-year of follow-up during the study period. The beginning of follow-up for the hepatology or primary care group was defined as the later of either the date of first date of each cohort study period or the date of first visit to each coinfection clinic model. The end of follow-up for each group was the earlier of either the date of last visit to the co-infection clinic model or the end of the two respective study periods. The referral rate ratio and 95\% confidence interval was estimated with its associated p- value. Analyses were performed using NCCSS version 8.0 (Kaysville, Utah, USA).

\section{Results}

From a total of 667 and $616 \mathrm{HIV} / \mathrm{HCV}$ co-infected patients during the studied periods, 256 and 203 were referred for $\mathrm{HCV}$ treatment evaluation to the HIV primary care and hepatology models, respectively. The $\mathrm{HCV}$ prevalence was similar during studied periods, HIV primary care model (17\%) and hepatology (18\%). The patient referral rate for $\mathrm{HCV}$ treatment did not differ during the 2 study periods, 0.12 vs. 0.10 /patient-year for HIV primary care and hepatology models [difference $-0.02,95 \%$ confidence intervals $(\mathrm{CI})-0.03$ to $0.06 ; \mathrm{p}=0.18$ ]. Main reasons for exclusion of 100 patients after initial visit are shown in Figure 1. The final study cohorts were composed of 196 and 163 patients for the HIV primary care and the hepatology models, respectively. Of note there was no difference in the proportion of patients excluded in both clinic models due to prior $\mathrm{HCV}$ treatment null-response (11/196 vs. 6/163; $\mathrm{p}=0.39)$, Figure 1 .

Patients referred to the HIV primary care model were older (median 48 vs. 45 years), had a higher proportion of non-hispanics (85 vs. 74\%) and reported more frequently heterosexual sex as HIV risk factor (24 vs. $15 \%$ ) than those referred to the hepatology model. They also had higher median CD4+ cell counts ( 431 vs. $372 / \mathrm{mm}^{3}$ ) and platelet counts $\left(208\right.$ vs. $\left.184 \times 103 / \mathrm{mm}^{3}\right)$ at the time of $\mathrm{HCV}$ treatment consideration (Table 1). There were

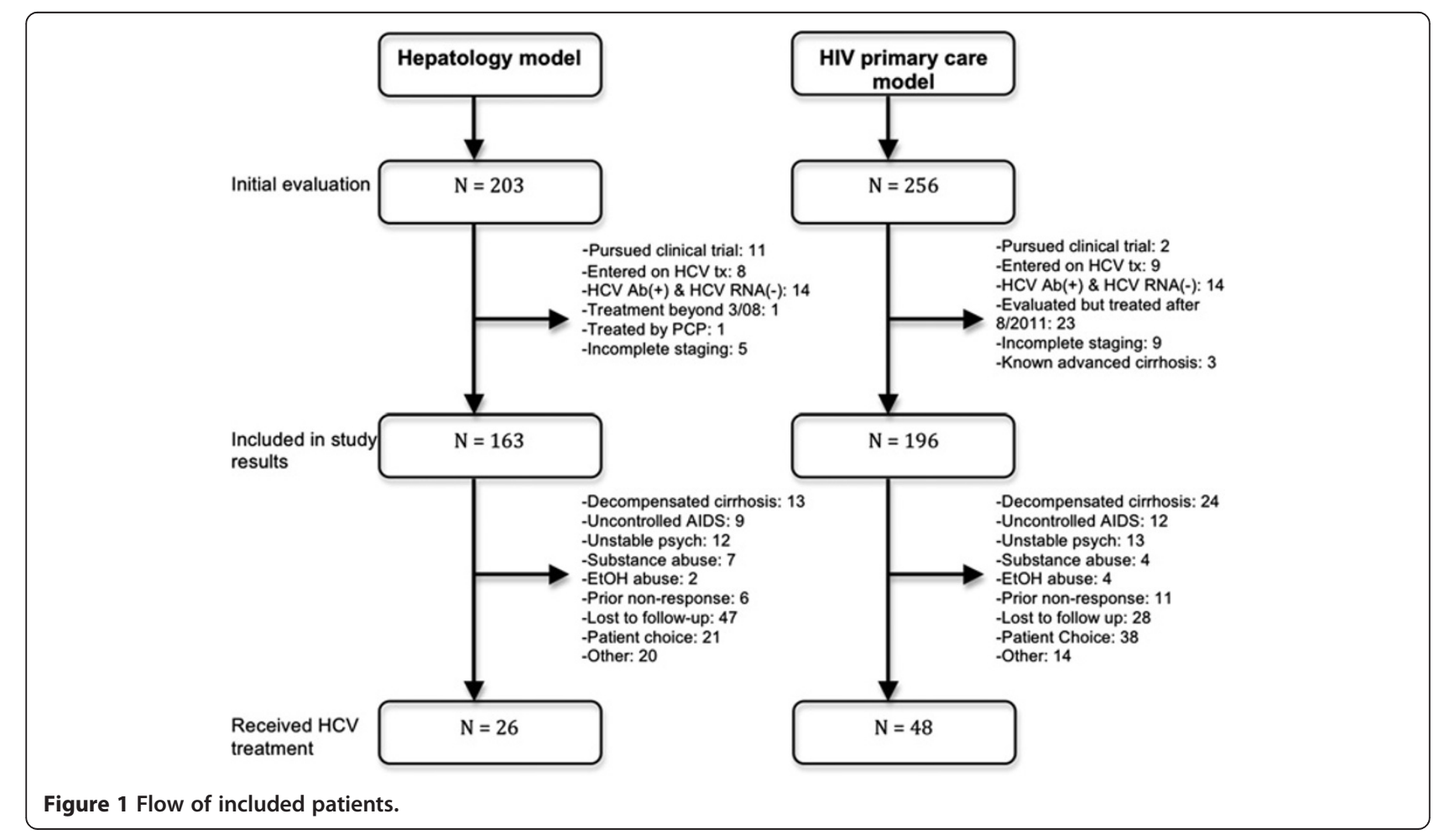


Table 1 Characteristics of the patients assessed for hepatitis C treatment consideration according to clinic model

\begin{tabular}{|c|c|c|c|}
\hline Clinic model & $\begin{array}{l}\text { Hepatology } \\
(n=163)\end{array}$ & $\begin{array}{l}\text { HIV primary care } \\
\qquad(n=196)\end{array}$ & $\begin{array}{c}P \\
\text { value }\end{array}$ \\
\hline Median age - years (range) & $45(26-73)$ & $48(19-75)$ & $0.02^{a}$ \\
\hline Sex: Male (\%) & $137(84)$ & $165(84)$ & $0.97^{\mathrm{b}}$ \\
\hline \multicolumn{4}{|l|}{ Race } \\
\hline White & 115 & 138 & \multirow[t]{4}{*}{$0.20^{c}$} \\
\hline Black & 39 & 50 & \\
\hline Asian & 0 & 3 & \\
\hline Other/unknown & 9 & 5 & \\
\hline \multicolumn{4}{|l|}{ Ethnicity } \\
\hline Hispanic & 35 & 26 & \multirow[t]{3}{*}{$0.03^{c}$} \\
\hline Not-Hispanic & 121 & 167 & \\
\hline Unknown & 7 & 3 & \\
\hline \multicolumn{4}{|l|}{ HIV risk factors } \\
\hline Gay/bisexual & 79 & 78 & \multirow[t]{6}{*}{$0.003^{c}$} \\
\hline Heterosexual & 24 & 46 & \\
\hline Intravenous drug use & 3 & 8 & \\
\hline Hemophilia & 8 & 5 & \\
\hline combination & 25 & 47 & \\
\hline Other/unknown & 24 & 12 & \\
\hline Median CD4+ cell count - cells $/ \mathrm{mm}^{3}$ (range) $)^{1}$ & $372(29-1179)$ & $431(38-1612)$ & $0.05^{\mathrm{a}}$ \\
\hline Median HIV load - $\log _{10}$ copies/mL (range) & $2.6(2.6-5.8)$ & $2.6(2.6-6.6)$ & $0.12^{\mathrm{a}}$ \\
\hline Number on HAART therapy - \% & $132(81)$ & $172(88)$ & $0.08^{\mathrm{b}}$ \\
\hline \multicolumn{4}{|l|}{ Hepatitis C genotype ${ }^{2}$} \\
\hline Genotype 1,4 & 125 & 158 & \multirow[t]{2}{*}{$0.68^{c}$} \\
\hline Genotype 2,3 & 31 & 35 & \\
\hline Median HCV load - $\log _{10}$ copies $/ \mathrm{mL}(\text { range) })^{3}$ & $6.29(1.9-8.4)$ & $6.43(2.2-8.4)$ & $0.43^{\mathrm{a}}$ \\
\hline \multicolumn{4}{|l|}{ Liver biopsy scores ${ }^{4}$} \\
\hline Fo-2 & 39 & 42 & \multirow[t]{2}{*}{$0.95^{\mathrm{c}}$} \\
\hline$F 3,4$ & 37 & 39 & \\
\hline Any neuropsychiatry history - \% & $100(61 \%)$ & $119(61 \%)$ & $0.85^{\mathrm{b}}$ \\
\hline On any psychiatry medications - \% & $75(46 \%)$ & $88(45 \%)$ & $0.83^{\mathrm{b}}$ \\
\hline \multicolumn{4}{|c|}{ Drugs or alcohol use within 3months of HCV treatment consideration } \\
\hline No & 71 & 115 & \multirow[t]{3}{*}{$0.0001^{\mathrm{C}}$} \\
\hline yes & 45 & 72 & \\
\hline unknown & 47 & 9 & \\
\hline Median hemoglobin levels - g/dL (range) & $14.7(9-18.7)$ & $14.3(7.7-17.6)$ & $0.13^{\mathrm{a}}$ \\
\hline Median platelet count $-1000 / \mathrm{mm}^{3}$ (range) & $184(44-531)$ & $208(41-548)$ & $0.004^{a}$ \\
\hline Median ALT - U/L (range) & $68(20-980)$ & $57(12-1280)$ & $0.51^{\mathrm{a}}$ \\
\hline Median INR (range) & $1.1(0.9-2.3)$ & $1.0(0.9-2.6)$ & $0.05^{\mathrm{a}}$ \\
\hline
\end{tabular}

$\mathrm{ALT}=$ Alanine aminotransferase $; \mathrm{AST}=$ Aspartate aminotransferase; INR = International normalized ratio.

${ }^{1}$ CD4+ counts available in 150 of 163 patients in the hepatology model and in all patients in HIV primary care model.

${ }^{2}$ HCV genotype was not available in seven patients in hepatology model and one in HIV primary care model.

${ }^{3}$ Liver biopsies: 70 in hepatology and 67 in HIV primary care models.

${ }^{4}$ Two patients in the hepatology model had no available HCV viral load.

a Wilcoxon Rank-Sum Test.

${ }^{\text {b }}$ Chi-square Test.

' Fisher's exact Test. 
Table 2 Characteristics of the patients treated for hepatitis C according to clinic model and treatment outcomes

\begin{tabular}{|c|c|c|c|}
\hline Clinic model & $\begin{array}{l}\text { Hepatology } \\
\quad(n=26)\end{array}$ & $\begin{array}{l}\text { HIV primary care } \\
\qquad(n=48)\end{array}$ & $\begin{array}{c}P \\
\text { value }\end{array}$ \\
\hline Median age - years (range) & $44(27-62)$ & $49(19-61)$ & $0.18^{a}$ \\
\hline Sex: Male (\%) & $23(88)$ & $38(79)$ & $0.32^{b}$ \\
\hline \multicolumn{4}{|l|}{ Race } \\
\hline White & 21 & 32 & \multirow[t]{3}{*}{$0.44^{c}$} \\
\hline Black & 4 & 13 & \\
\hline Other/unknown & 1 & 3 & \\
\hline \multicolumn{4}{|l|}{ Ethnicity } \\
\hline Hispanic & 5 & 7 & \multirow[t]{3}{*}{$0.12^{\mathrm{c}}$} \\
\hline Not-Hispanic & 19 & 41 & \\
\hline Unknown & 2 & 0 & \\
\hline \multicolumn{4}{|l|}{ HIV risk factors } \\
\hline Gay/bisexual & 8 & 21 & \multirow[t]{6}{*}{$0.008^{c}$} \\
\hline Heterosexual & 5 & 14 & \\
\hline Intravenous drug use & 1 & 0 & \\
\hline Hemophilia & 3 & 0 & \\
\hline combination & 3 & 11 & \\
\hline Other/unknown & 6 & 2 & \\
\hline Median CD4+ cell count - cells $/ \mathrm{mm}^{3}$ (range) & $375(149-1179)$ & $522(130-1142)$ & $0.02^{\mathrm{a}}$ \\
\hline Number with undetectable HIV load (\%) & $22(85)$ & $29(83)$ & $0.88^{\mathrm{b}}$ \\
\hline \multicolumn{4}{|l|}{ Hepatitis C genotype ${ }^{2}$} \\
\hline Genotype 1/4 & 19 & 39 & \multirow[t]{2}{*}{$0.42^{\mathrm{b}}$} \\
\hline Genotype 2/3 & 7 & 9 & \\
\hline Median HCV load - $\log _{10}$ copies/mL (range) & $6.04(5.1-7.7)$ & $6.41(3.0-7.6)$ & $0.88^{\mathrm{a}}$ \\
\hline \multicolumn{4}{|l|}{ Liver biopsy scores $^{1}$} \\
\hline F0-2 & 8 & 12 & \multirow[t]{2}{*}{$0.37^{c}$} \\
\hline$F 3,4$ & 9 & 23 & \\
\hline Number with relapse after prior HCV treatment (\%) & $5(19)$ & $5(11)$ & $0.29^{b}$ \\
\hline Any neuropsychiatry history - \% & $17(65)$ & $23(48)$ & $0.15^{\mathrm{b}}$ \\
\hline On any psychiatry medications - \% & $11(42)$ & $15(31)$ & $0.34^{\mathrm{b}}$ \\
\hline \multicolumn{4}{|l|}{ Drugs or alcohol use within 3months of HCV treatment consideration } \\
\hline No & 12 & 32 & \multirow[t]{3}{*}{$0.0001^{\mathrm{C}}$} \\
\hline Yes & 5 & 16 & \\
\hline Unknown & 9 & 0 & \\
\hline Median hemoglobin levels - g/dL (range) & $14.8(11.1-16.9)$ & $14.5(12.1-16.6)$ & $0.17^{\mathrm{a}}$ \\
\hline Median platelet count $-1000 / \mathrm{mm}^{3}$ (range) & $178(56-367)$ & $224(113-418)$ & $0.01^{\mathrm{a}}$ \\
\hline Median ALT - U/L (range) & $71(22-980)$ & $64(19-1087)$ & $0.48^{\mathrm{a}}$ \\
\hline Median INR (range) & $1.1(0.9-1.4)$ & $1.0(0.9-1.2)$ & $0.69^{a}$ \\
\hline \multicolumn{4}{|l|}{ HCV treatment outcomes } \\
\hline № Patients with rapid viral response (\%) & $4(15)$ & $12(25)$ & $0.34^{\mathrm{b}}$ \\
\hline № Patients with complete early viral response (\%) & $9(35)$ & $26(54)$ & $0.11^{\mathrm{b}}$ \\
\hline № Patients with end of treatment response (\%) & $12(46)$ & $24(50)$ & $0.75^{\mathrm{b}}$ \\
\hline № Patients with sustained viral response (\%) & $9(35)$ & $21(44)$ & $0.45^{\mathrm{b}}$ \\
\hline № Patients who discontinued HCV therapy due to non-viral response (\%) & $8(31)$ & $9(19)$ & $0.24^{b}$ \\
\hline
\end{tabular}


Table 2 Characteristics of the patients treated for hepatitis $\mathrm{C}$ according to clinic model and treatment outcomes (Continued)

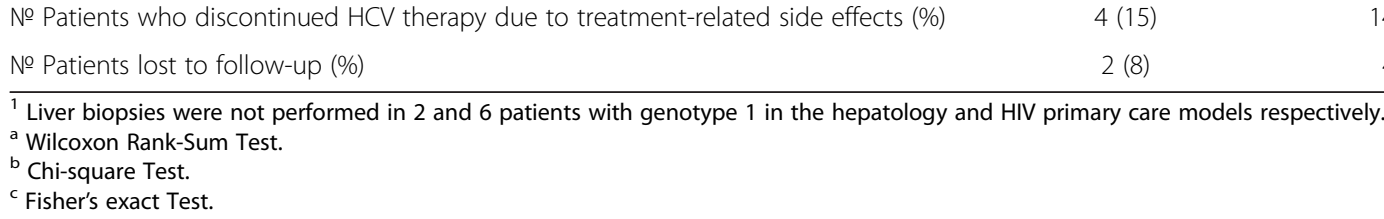

${ }^{1}$ Liver biopsies were not performed in 2 and 6 patients with genotype 1 in the hepatology and HIV primary care models respectively

a Wilcoxon Rank-Sum Test.

${ }^{\mathrm{b}}$ Chi-square Test.

' Fisher's exact Test.

no differences between clinic model cohorts of referred patients in plasma HIV or HCV viral load, HCV genotype distribution, liver fibrosis score, proportion of patients -receiving HIV therapy, -with neuropsychiatric history, -on psychotropic medications. Among patients referred to the HIV primary care model, $37 \%$ reported use of drugs or heavy alcohol within 3 months of $\mathrm{HCV}$ treatment consideration (Table 1).

While in the HIV primary care model a higher proportion of patients (19 vs. 13\%) chose to defer HCV therapy due to personal reasons (e.g. did not want to request time off at work), in the hepatology model more patients failed to initiate $\mathrm{HCV}$ therapy due to loss-to-follow up (29 vs. $14 \%$ ), overall comparison $\chi^{2} 15.6, \mathrm{df}=8, \mathrm{p}=$ 0.03 (Figure 1).

\section{Treatment rates and predictors of Hepatitis $\mathrm{C}$ treatment}

More patients were treated for HCV in the HIV primary care model than in the hepatology model ( 48 vs. $26, \mathrm{p}=$ 0.043). This difference was more apparent in the second year of implementation of the HIV primary care model, when comparing the proportion of patients treated for HCV by year of study periods: year 1 ( 9 vs. 13\%), year 2 (35 vs. $11 \%$ ), year 3 (44 vs. $28 \%$ ), for HIV primary care vs. hepatology models, respectively, $x^{2} 8.1, \mathrm{df}=2$, $\mathrm{p}=0.02$.

Patients treated in the HIV primary care model had a higher median CD4+ cell count (522 vs. $375 / \mathrm{mm}^{3}$ ), platelet count ( 224 vs. $178 \times 10^{3} / \mathrm{mm}^{3}, \mathrm{p}=0.01$ ) and frequency of drugs or alcohol use within 3 months of HCV therapy evaluation (33 vs. 19\%). Among those treated for HCV, there were no differences between clinic models in the age, race/ethnicity, HIV/HCV viral load, proportion on HIV therapy, HCV genotype distribution, liver fibrosis score, relapse after prior HCV treatment or prevalence of psychiatric disease (Table 2). When comparing clinical characteristics of $\mathrm{HCV}$ treated and untreated patients within each model, in the hepatology model there were no clinical variables associated with the decision to initiate $\mathrm{HCV}$ treatment. However, patients treated for $\mathrm{HCV}$ under the HIV primary care model had higher CD4+ cell counts, lower rates of psychiatric illness, and were prescribed fewer psychotropic medications (Table 3). Using bivariate categorical analysis, independent predictors of $\mathrm{HCV}$ therapy initiation included being referred to the HIV primary care model [odds ratio (OR) 1.8, 95\% CI 1.1-2.9, $\mathrm{p}=0.04]$; having a higher CD4+ count $(\geq 400 / \mathrm{mm} 3$, OR: 1.8, 95\% CI 1.1-3.0) and ALT levels (> 63 U/L, OR: 1.9, $95 \%$ CI 1.2-2.9). Prior psychiatric medication use correlated negatively with $\mathrm{HCV}$ treatment initiation (OR: 0.6, 95\% CI 0.3-0.99). Logistic regression analysis adjusting for all aforementioned significant variables showed that the strongest predictor of $\mathrm{HCV}$ treatment initiation was CD4+ count ( $\geq 400 / \mathrm{mm} 3$, OR: $2.1,95 \%$ CI $1.2-3.6, \mathrm{p}=$ 0.01 ) whereas a history of prior psychiatric medication use decreased the chances of HCV treatment initiation (OR: 0.5, 95\% CI 0.3-0.9, $\mathrm{p}=0.02$ ), (Table 4).

\section{Outcomes of HCV treatment}

Similar proportions of patients achieved undetectable HCV viral load -at week 4 (rapid viral response [RVR]), at week 12 (complete early viral response [cEVR]) and at week 48 (end of treatment response [ETR]) in both models (HIV primary care vs. hepatology): RVR [12/48(25\%) vs. 4/ 26(15\%)], cEVR [26/48(54\%) vs. 9/26(35\%)] and ETR (24/ $48(50 \%$, vs. $12 / 26(46 \%)]$. Twenty-one of 48 patients (44\%) in the HIV primary care and 9 of 26 patients $(35 \%)$ in the hepatology model achieved HCV SVR ( $\mathrm{p}=0.45)$.

When comparing both models (primary care vs. hepatology), there were no differences in the overall $\mathrm{HCV}$ treatment discontinuations rates $[27 / 48(56 \%)$ vs. $14 / 26$ (54\%), $\mathrm{p}=0.84$ ] or cause-specific reasons HCV-treatment discontinuation rates: (1) non-viral response [9 /48 (18\%) vs. $8 / 26$ (31\%), $\mathrm{p}=0.24]$; (2) HCV therapy-related adverse events [14/48 (29\%) vs. $4 / 26(16 \%), \mathrm{p}=0.19]$; and loss to follow-up (4/ 48 (8\%) vs. $2 / 26(8 \%), \mathrm{p}=0.92$ ]. The median time for HCV treatment discontinuation due to adverse events in the HIV primary care model was 12 weeks (range 1-55) and was comparable to the hepatology model (median 8 weeks, range 1-40). The reasons for treatment discontinuation in the hepatology model $(\mathrm{n}=4)$ were hematologic (2) and neuropsychiatric (2) side effects. In the HIV primary care model, main reasons for adverseevents HCV treatment discontinuation $(\mathrm{n}=14)$ were neuropsychiatric (7) and somatic (7) side effects. The somatic side effects included: severe fatigue (3), anorexia /weight loss (2), dizziness (1) and skin rash (1). In the HIV primary care model, 16 (33\%) HCV treated patients were actively 
Table 3 Comparison of characteristics of the treated vs. untreated patients for hepatitis $\mathbf{C}$ according to clinic model

\begin{tabular}{|c|c|c|c|c|c|c|}
\hline \multirow[t]{2}{*}{ Clinic Model } & \multicolumn{3}{|c|}{ Hepatology } & \multicolumn{3}{|c|}{ HIV Primary care } \\
\hline & $\begin{array}{l}\text { Treated } \\
(n=26)\end{array}$ & $\begin{array}{c}\text { Not treated } \\
(n=137)\end{array}$ & $P$ & $\begin{array}{l}\text { Treated } \\
(n=48)\end{array}$ & $\begin{array}{c}\text { Not treated } \\
(n=148)\end{array}$ & $P$ \\
\hline Median age - years (range) & $44(27-62)$ & $45(26-73)$ & $0.73^{a}$ & 49 (19-61) & $48(23-75)$ & $0.46^{\mathrm{a}}$ \\
\hline Sex: Male (\%) & $23(89)$ & $114(83)$ & $0.50^{\mathrm{b}}$ & $38(79)$ & $127(86)$ & $0.27^{b}$ \\
\hline \multicolumn{7}{|l|}{ Race } \\
\hline White & 21 & 94 & $0.46^{c}$ & 32 & 106 & $0.63^{c}$ \\
\hline Black & 4 & 35 & & 13 & 37 & \\
\hline Other/unknown & 1 & 8 & & 2 & 5 & \\
\hline \multicolumn{7}{|l|}{ Ethnicity } \\
\hline Hispanic & 5 & 30 & $0.64^{c}$ & 7 & 19 & $0.59^{c}$ \\
\hline Not-Hispanic & 19 & 102 & & 41 & 16 & \\
\hline Unknown & 2 & 5 & & 0 & 3 & \\
\hline \multicolumn{7}{|l|}{ HIV risk factors } \\
\hline Gay/bisexual & 8 & 71 & $0.18^{c}$ & 21 & 57 & $0.33^{c}$ \\
\hline Heterosexual & 5 & 19 & & 14 & 32 & \\
\hline Intravenous drug use & 1 & 2 & & 0 & 8 & \\
\hline Hemophilia & 3 & 5 & & 0 & 5 & \\
\hline combination & 3 & 22 & & 11 & 36 & \\
\hline Other/unknown & 6 & 18 & & 2 & 10 & \\
\hline Median CD4+ cell count - cells $/ \mathrm{mm}^{3}$ (range) & $375(149-1179)$ & $\begin{array}{c}371(29- \\
1025)\end{array}$ & $0.68^{\mathrm{a}}$ & $522(130-1142)$ & $388(38-1612)$ & $0.005^{\mathrm{a}}$ \\
\hline Number of patients on HIV therapy (\%) & $22(85 \%)$ & $110(80 \%)$ & $0.61^{b}$ & $44(92 \%)$ & $128(87 \%)$ & $0.74^{\mathrm{b}}$ \\
\hline Number with undetectable HIV load (\%) & $22(85 \%)$ & 95 (69\%) & $0.11^{\mathrm{b}}$ & $40(83 \%)$ & $115(78 \%)$ & $0.41^{\mathrm{b}}$ \\
\hline \multicolumn{7}{|l|}{ Hepatitis C genotype ${ }^{1}$} \\
\hline Genotype 1/4 & 19 & 106 & $0.32^{c}$ & 39 & 119 & $0.90^{\mathrm{b}}$ \\
\hline Genotype 2/3 & 7 & 24 & & 9 & 26 & \\
\hline Median HCV load $-\log _{10}$ copies $/ \mathrm{mL}(\text { range })^{2}$ & $6.0(5.1-7.7)$ & $6.3(1.9-8.4)$ & $0.71^{a}$ & $6.4(3.01-7.6)$ & $6.4(2.2-8.4)$ & $0.19^{\mathrm{a}}$ \\
\hline \multicolumn{7}{|l|}{ Liver biopsy scores } \\
\hline FO-2 & 8 & 31 & $0.10^{c}$ & 12 & 30 & $0.19^{c}$ \\
\hline F3-4 & 9 & 28 & & 13 & 26 & \\
\hline unknown & 9 & 78 & & 23 & 92 & \\
\hline Any neuropsychiatry history - \% & $17(65 \%)$ & $83(61 \%)$ & $0.65^{\mathrm{b}}$ & $23(48 \%)$ & $96(65 \%)$ & $0.04^{b}$ \\
\hline On any psychiatry medications - $\%$ & $11(42 \%)$ & $64(47)$ & $0.68^{\mathrm{b}}$ & $15(31 \%)$ & 73(49) & $0.03^{b}$ \\
\hline \multicolumn{7}{|c|}{$\begin{array}{l}\text { Drugs or alcohol use within 3months of HCV treatment } \\
\text { consideration }\end{array}$} \\
\hline No & 12 & 59 & $0.55^{c}$ & 32 & 83 & $0.15^{c}$ \\
\hline Yes & 5 & 40 & & 16 & 56 & \\
\hline Unknown & 9 & 38 & & 0 & 9 & \\
\hline Median hemoglobin levels - g/dL (range) & $\begin{array}{l}14.8(11.1- \\
16.9)\end{array}$ & $14.7(9-18.7)$ & $0.37^{\mathrm{a}}$ & $\begin{array}{l}14.5(12.1- \\
16.6)\end{array}$ & $\begin{array}{l}14.2(7.7- \\
17.6)\end{array}$ & $0.67^{\mathrm{a}}$ \\
\hline Median platelet count $-1000 / \mathrm{mm}^{3}$ (range) & $178(56-367)$ & $185(44-531)$ & $0.47^{\mathrm{a}}$ & $224(113-418)$ & $207(41-548)$ & $0.18^{\mathrm{a}}$ \\
\hline
\end{tabular}




\section{Table 3 Comparison of characteristics of the treated vs. untreated patients for hepatitis $\mathrm{C}$ according to clinic model} (Continued)

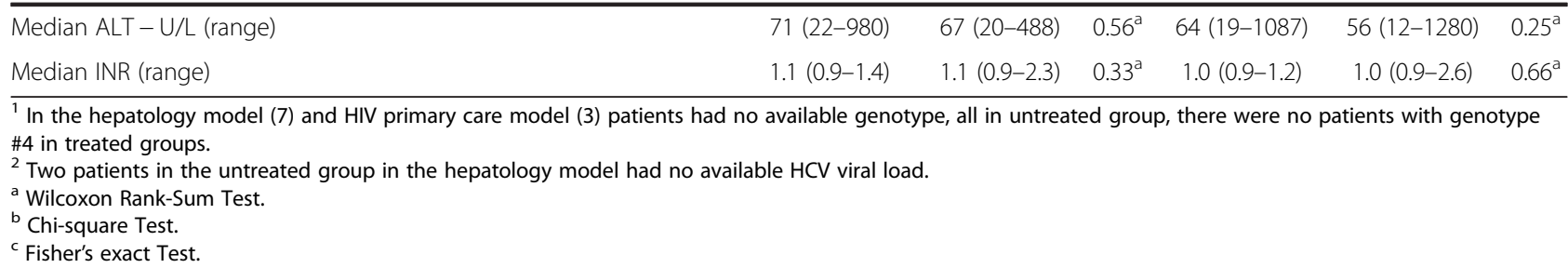

using illicit substances of whom 2 were using intravenous drugs and 4 were homeless. None of the treated homeless patients were lost to follow-up.

Among patients treated in the HIV primary care model, 17 were considered high-risk: substance use and/ or homelessness $(\mathrm{n}=10)$ and severe psychiatric and/or medical comorbidities $(n=7)$. The group of 'high-risk' patients was assigned to special HCV treatment monitoring strategies as described in Additional file 1: Table S1. There were no statistical differences between high-risk vs. non high-risk patients in the rates of SVR, discontinuations due to non-viral response or HCV therapy-related adverse events or loss to follow-up (Table 5). However, the difference in point estimates for loss to follow-up (18\% vs. $3 \%[\mathrm{p}=0.08]$ for high and non-high risk, respectively) partially validates the criteria we used to identify high risk patients.

\section{Discussion}

Our comparison of the performance of an HIV primary care model for the treatment of HCV among HIV-infected patients in comparison to a subspecialty hepatology model allows the following conclusions to be made: (1) In the HIV primary care model there were more patients treated for HCV and fewer were lost to follow-up; (2) HCV treatment referral rates did not differ during two study periods; (3) discontinuation rates were similar in both models despite the increased prevalence of ongoing substance use in the HIV primary care model; (4) the rate of HCV cure (SVR) was similar in both clinic models.

The idea of using an HIV primary care model for the treatment of HCV is not new [8,14-17]. However, a novel component of our approach was the integration of HIV clinical pharmacists to enhance protocol adherence and patient safety. Undoubtedly, the role of the pharmacists is becoming more prominent since the introduction of $\mathrm{HCV}$ direct acting antivirals in co-infected individuals, where attention to medication interactions is particularly important [18].

The patient referral rate for HCV treatment did not increase during the HIV primary care model, but referred patients had less obvious clinical or laboratory signs of decompensated liver disease such as thrombocytopenia or coagulopathy (Table 2). It is not clear whether this was the result of the increased awareness among HIV providers about importance of HCV treatment in the HIV primary care model. What is known is that in the HIV primary care model, $33 \%$ of patients treated for HCV had history of ongoing substance use and 4 patients were homeless. Despite this 'high risk population' treated for HCV by the HIV primary care model, the proportions of HCV treatment discontinuation (either due to adverse events or loss to follow-up) and cure were similar to the hepatology model. Moreover, the treatment outcomes in the high-risk patients were similar to the non-high risk patients treated in the HIV primary care model. In particular there was no difference in the rate of treatment discontinuation due to adverse events (Table 5). We acknowledge that our samples size was small to detect as significant differences between high-risk and non-high risk treated patients. But the message to highlight is that the collaborative monitoring strategy use by the HIV primary care model allowed the HCV cure of patients that may have been rendered unfavorable $\mathrm{HCV}$ treatment candidates in other subspecialty models [2]. The finding that patients with unstable psychiatric conditions, higher HIV viral loads and lower CD4 cell counts were less likely to be treated in the HIV primary care model was in line with the Owen Clinic protocol of working prospectively with patients to link them to care and, once they are more stable and engaged, initiate HCV therapy [19]. This contrasted with the lack of association with any of the studied variables to predict HCV therapy initiation in the hepatology model.

The present study found no significant differences in the rates of HCV SVR and discontinuation of HCV therapy due to adverse events, however, the SVR trend was greater in patients treated on the HIV primary care clinic (44 vs. 35\%) despite having almost double discontinuations due to adverse events of patients treated by the hepatology clinic ( 29 vs. $16 \%$ ), perhaps due our lack of sample size to detect those differences as significant (e.g. current sample size has $10 \%$ power to detect a difference of $9 \%$ in SVR as significant). In the absence of a difference in the proportion of patients with viral relapse after prior HCV therapy in both treatment models, we believe that this observation may be explained by unmeasured clinical factors such as: 1) potential better interleukin-28B gene polymorphism allele profile in patients treated in the HIV primary care 
Table 4 Predictors of Hepatitis C treatment among patients referred to the hepatology $(n=163)$ and HIV primary care models $(n=196)$ in unadjusted and adjusted analyses

\begin{tabular}{|c|c|c|c|c|}
\hline Covariate & $\begin{array}{l}\text { Unadjusted } \\
\text { OR }(95 \% \mathrm{Cl})\end{array}$ & $\begin{array}{c}P \\
\text { value }\end{array}$ & $\begin{array}{c}\text { Adjusted } \\
\text { OR }(95 \% \mathrm{Cl})\end{array}$ & $\begin{array}{c}P \\
\text { value }\end{array}$ \\
\hline \multicolumn{5}{|l|}{ Hepatitis C treatment } \\
\hline (HIV primary care vs. hepatology model ) & $1.7(1.0-2.9)$ & 0.04 & $1.6(0.9-2.8)$ & 0.08 \\
\hline \multicolumn{5}{|l|}{ CD4+ cell count ${ }^{1}$} \\
\hline$\left(\geq 400\right.$ vs. $<400$ cells $/ \mathrm{mm}^{3}$ ) & $1.8(1.1-3.03)$ & 0.03 & $2.1(1.2-3.6)$ & 0.01 \\
\hline \multicolumn{5}{|l|}{ Having detectable HIV load } \\
\hline ( $\geq 400$ vs. $<400$ copies $/ m L$ ) & $0.5(0.3-1.1)$ & 0.09 & $0.6(0.3-1.1)$ & 0.09 \\
\hline \multicolumn{5}{|l|}{ On any psychiatry medications } \\
\hline (any vs. none) & $0.6(0.3-0.99)$ & 0.04 & $0.5(0.3-0.9)$ & 0.02 \\
\hline \multicolumn{5}{|l|}{ Alanine aminotransferase levels } \\
\hline ( $\geq 63$ vs. $<63 \mathrm{U} / \mathrm{L})$ & $1.9(1.2-2.9)$ & 0.002 & $1.4(0.8-2.3)$ & 0.3 \\
\hline
\end{tabular}

Any neuropsychiatry history

(yes vs. no)

$0.7(0.4-1.2)$

0.17

Age - years

Per year increase

$1.0(0.9-1.03)$

Sex-biological

(male vs. female)

$1.2(0.6-2.3)$

0.65

Race

(white vs. non-white)

$1.2(0.6-2.5)$

Ethnicity:

(non-hispanic vs. hispanic)

$1.6(0.2-13.4)$

HIV risk factors

Men having sex with men

Reference

Heterosexual

$1.6(0.9-3.2)$

0.14

Intravenous drug use

$0.4(0.1-3.6)$

0.44

Hemophilia

$1.3(0.3-5.1)$

0.68

Combination

$1.1(0.5-2.1)$

Hepatitis C genotype ${ }^{2}$

(1/4 vs. 2/3)

$0.8(0.4-1.5)$

0.50

Liver biopsy scores ${ }^{3}$

(Proportion F3-4 vs. F0-2)

$1.2(0.6-2.5)$

Drugs or alcohol use within 3 months of

HCV evaluation ${ }^{4}$

(yes vs. no)

$0.7(0.4-1.3)$

HCV load - $\log _{10}$ copies $/ \mathrm{mL}^{5}$

(>6.33 vs. $\leq 6.33$ )

$0.8(0.5-1.4)$

Hemoglobin levels

(>14.1 vs. $\leq 14.1 \mathrm{~g} / \mathrm{dL}$ )

$1.5(0.8-2.6)$

Platelet count 
Table 4 Predictors of Hepatitis C treatment among patients referred to the hepatology $(n=163)$ and HIV primary care models $(n=196)$ in unadjusted and adjusted analyses (Continued)

$\left(>139\right.$ vs. $\left.\leq 139-1000 / \mathrm{mm}^{3}\right)$
INR levels
$(>1.1$ vs. $\leq 1.1)$
${ }^{1} \mathrm{CD} 4+$ counts available in 150 of 163 patients in the hepatology model and in all patients in HIV primary care model.
${ }^{2} \mathrm{HCV}$ genotype was not available in seven patients in hepatology model and one in HIV primary care model.
${ }^{3}$ Liver biopsies: 70 in hepatology and 67 in HIV primary care models.
${ }^{4}$ No data available in 47 patients in the hepatology model and in 9 patients in the HIV primary care model.
${ }^{5}$ Two patients in the hepatology model had no available HCV viral load.

Table 5 Characteristics and outcomes of patients treated for hepatitis C in the HIV primary care model dichotomized according to risk category based on assigned HCV treatment monitoring group*

\begin{tabular}{|c|c|c|c|}
\hline Clinic model & $\begin{array}{l}\text { High-risk } \\
(n=17)\end{array}$ & $\begin{array}{l}\text { Non-high-risk } \\
\quad(n=31)\end{array}$ & $\begin{array}{c}P \\
\text { value }\end{array}$ \\
\hline Median age - years (range) & $49(19-61)$ & $47(33-61)$ & $0.77^{a}$ \\
\hline Sex: Male (\%) & $14(82)$ & $24(77)$ & $0.68^{b}$ \\
\hline \multicolumn{4}{|l|}{ Race } \\
\hline White & 13 & 19 & \multirow[t]{3}{*}{$0.14^{c}$} \\
\hline Black & 2 & 11 & \\
\hline Other/unknown & 2 & 1 & \\
\hline \multicolumn{4}{|l|}{ Ethnicity } \\
\hline Hispanic & 2 & 5 & \multirow[t]{2}{*}{$0.68^{c}$} \\
\hline Not-Hispanic & 15 & 26 & \\
\hline Median T CD4+ cell count - cells/mm³ (range) & $515(130-1136)$ & $529(170-1140)$ & $0.55^{\mathrm{a}}$ \\
\hline Number with undetectable HIV load (\%) & $14(82)$ & $26(84)$ & $0.91^{b}$ \\
\hline \multicolumn{4}{|l|}{ Hepatitis C genotype } \\
\hline Genotype 1/4 & 13 & 26 & \multirow[t]{2}{*}{$0.53^{b}$} \\
\hline Genotype 2/3 & 4 & 5 & \\
\hline Median HCV load - $\log _{10}$ copies/mL (range) & $6.44(4.05-7.46)$ & $6.40(3.0-7.6)$ & $0.73^{\mathrm{a}}$ \\
\hline \multicolumn{4}{|l|}{ Liver biopsy scores ${ }^{1}$} \\
\hline $\mathrm{FO}-2$ & 4 & 8 & \multirow[t]{2}{*}{$0.51^{\mathrm{c}}$} \\
\hline $\mathrm{F} 3,4$ & 6 & 7 & \\
\hline Median Hemoglobin levels - g/dL (range) & $14.5(12.9-15.8)$ & 14.4(12.1-16.6) & $0.63^{a}$ \\
\hline Median Platelet count -1000/mm³ (range) & $191(113-418)$ & $227(119-402)$ & $0.38^{a}$ \\
\hline Median ALT - U/L (range) & $85(22-301)$ & $56(19-1087)$ & $0.08^{a}$ \\
\hline \multicolumn{4}{|l|}{ HCV treatment outcomes } \\
\hline № Patients with Sustained viral response (\%) & $5(29)$ & $16(52)$ & $0.14^{b}$ \\
\hline № Patients who discontinued HCV therapy due to non-viral response (\%) & $2(12)$ & $7(23)$ & $0.36^{b}$ \\
\hline № Patients who discontinued HCV therapy due to treatment-related side effects (\%) & $6(35)$ & $8(26)$ & $0.49^{b}$ \\
\hline № Patients lost to follow-up (\%) & $3(18)$ & $1(3)$ & $0.08^{b}$ \\
\hline
\end{tabular}

* High-risk patients comprised patients with substance use and/or homelessness $(n=10)$ and severe psychiatry and/or medical comorbidities ( $n=7)$.

${ }^{1}$ Liver biopsies were not performed in 6 patients with genotype 1 in the high-risk $(n=3)$ and non-high risk $(n=3)$ respectively.

a Wilcoxon Rank-Sum Test.

${ }^{\mathrm{b}}$ Chi-square test.

c Fisher's exact test. 
model [20], since this test was not available in our institution at the time we performed study; 2) a positive effect of HIV primary care model in motivating patients while on $\mathrm{HCV}$ therapy that led to improved adherence and hence chances of cure in those who were able to tolerate $\mathrm{HCV}$ therapy [21]. This study has important limitations. First, this was not a randomized clinical trial; rather the aim was to compare the performance of 2 clinic-based models with balanced and overall comparable study populations. Second, the HIV primary care model did not treat patients with advanced cirrhosis given that these individuals are more prone to develop severe adverse events. Thus, our findings do not apply to patients with advanced liver disease, who still stand to benefit from specialized care by hepatologists. Third, we cannot rule out that the increasing rates of $\mathrm{HCV}$ treatment initiation over time in the HIV primary care model could be the result of secular trends: (a) aging of cohort and more urgency for treatment, (albeit we found no difference in liver fibrosis scores in both cohorts when liver biopsies were performed); (b) concurrent emphasis in the literature of epidemiologic evidence that liver disease is one of the leading causes of death in HIV-infected people, which may have motivated more treatment [22]. It could be argued that HCV treatment uptake rate in the HIV primary care model was not ideal (25\%). However, our reported HCV-treatment rates are higher than a recently reported aggressive program to engage $\mathrm{HIV} / \mathrm{HCV}$ co-infected patients in care sponsored by the United States National Institutes of Health [23] and similar to many European countries,[24] despite the fact we had considerably less accrual time than other clinicbased studies [16]. We believe that our study results underestimate the positive impact of the HIV primary care model in the HCV treatment uptake rate, since 23 patients in this model were excluded from the analysis because: (1) Three patients were still receiving HCV therapy and therefore we could not assess their final outcomes; (2) twenty patients who were staged and eligible for conventional $\mathrm{HCV}$ therapy within study period elected to wait for $\mathrm{HCV}$ protease inhibitors availability and initiated $\mathrm{HCV}$ treatment right before or after 30 July 2011, (Figure 1).

The fact that $10 \%$ of patients in both cohorts presented with advanced cirrhosis and were not eligible for $\mathrm{HCV}$ therapy highlights the importance of reducing disparities in access to HCV care in the HIV population $[3,25]$. New HCV therapies offer higher chances of cure, simpler and hopefully less toxic regimens [26,27]. However, to scale up HCV treatment among the HIV infected population, we will need an inclusive collaborative approach that reduces the negative referral bias of physicians when making $\mathrm{HCV}$ treatment decisions in vulnerable populations with ongoing barriers to care $[22,28,29]$. We believe that the HIV primary care model could be useful in other settings and countries burdened by the high prevalence of $\mathrm{HCV}$ and difficult to treat urban, poor, marginalized populations that require both more efficacious $\mathrm{HCV}$ therapies and newer collaborative models of care such as the one described here [30].

In conclusion, in this exploratory analysis, the use of an HIV primary care model supported by pharmacists specialized in HIV care increased the number of patients who initiate and successfully finish HCV therapy with comparable virological outcomes to a subspecialty hepatology model, highlighting the importance of increasing the absolute number of HIV-infected patients treated for $\mathrm{HCV}$ at any given time.

\section{Additional files}

Additional file 1: Table S1. Clinic visit schedule for HIV patients on HCV treatment based on their specific barriers and/or medical comorbidities (in weeks).

Additional file 2: Table S2. Minimal laboratory monitoring for HIV coinfected patients while on HCV treatment with pegylated Interferon and ribavarin ${ }^{1}$ (time in weeks).

\section{Competing interests}

The authors have no conflict of interest.

\section{Authors' contributions}

EC Clinical care, IRB request supervision, study design, data collection, data analyses and manuscript preparation. LH, Clinical care, IRB preparation and submission, study design, data collection and data analyses. CB, BC study design, IRB request supervision and clinical care. FT \& DW clinical care. Wm CM, study design, IRB submission supervision and data analyses. All authors read and approved the final manuscript.

\section{Acknowledgements}

We would like to thank Ms. Susan McQuillen for administrative assistance and Joe Montanez for providing substance counseling to our patients.

\section{Funding}

This work was supported in part by the Clinical Investigation Core of the University of California San Diego Center for AIDS Research [AI036214], the CFAR Network of Integrated Clinical Systems (CNICS) [R24 AI067039-01A1], and the Pacific AIDS Education and Training Center (PAETC). The funders had no role in study design, data collection and analysis, decision to publish, or preparation of the manuscript.

\section{Author details}

'Department of Medicine, Owen Clinic, University of California at San Diego, 200 W. Arbor Drive, San Diego, CA 92103-8681, USA. ² Kkaggs School of Pharmacy and Pharmaceutical Sciences, University of California at San Diego, San Diego, CA, USA. ${ }^{3}$ Department of Medicine, Division of Infectious Diseases, University of California at San Diego, San Diego, CA, USA.

\section{Received: 4 February 2013 Accepted: 21 March 2013}

Published: 28 March 2013

\section{References}

1. Scott JD, Wald A, Kitahata M, et al: Hepatitis C virus is infrequently evaluated and treated in an urban HIV clinic population. AIDS Patient Care STDS 2009, 23:925-929.

2. Vellozzi C, Buchacz K, Baker R, et al: Treatment of hepatitis C virus (HCV) infection in patients coinfected with HIV in the HIV Outpatient Study (HOPS), 1999-2007. J Viral Hepat 2011, 18:316-324.

3. Reiberger $T$, Obermeier M, Payer BA, et al: Considerable under-treatment of chronic HCV infection in HIV patients despite acceptable sustained 
virological response rates in a real-life setting. Antivir Ther 2011, 16:815-824.

4. Gordon S, Pockros P, Terrault N, et al: Impact of disease severity on health care costs in patients with chronic hepatitis $\mathrm{C}(\mathrm{CHC})$ virus infection. Hepatology 2012, 56:1651-1660

5. Norton BL, Park L, McGrath LJ, Proeschold Bell RJ, Muir AJ, Naggie S: Health care utilization in HIV-infected patients: assessing the burden of hepatitis C virus coinfection. AIDS Patient Care STDS 2012, 26:541-545.

6. Goulet JL, Fultz SL, McGinnis KA, Justice AC: Relative prevalence of comorbidities and treatment contraindications in HIV-mono-infected and HIV/HCV-co-infected veterans. AIDS 2005, 19(Suppl 3):S99-S105.

7. Golden J, O'Dwyer AM, Conroy RM: Depression and anxiety in patients with hepatitis C: prevalence, detection rates and risk factors. Gen Hosp Psychiatry 2005, 27:431-438.

8. Fleming CA, Tumilty S, Murray JE, Nunes D: Challenges in the treatment of patients coinfected with HIV and hepatitis $C$ virus: need for team care. Clin Infect Dis 2005, 40(Suppl 5):S349-S354

9. Lekas HM, Siegel K, Leider J: Challenges facing providers caring for HIV/ HCV-coinfected patients. Qual Health Res 2012, 22:54-66.

10. Astell-Burt T, Flowerdew R, Boyle P, Dillon J: Is travel-time to a specialist centre a risk factor for non-referral, non-attendance and loss to followup among patients with hepatitis C (HCV) infection? Soc Sci Med 2012, 75:240-247.

11. Preau M, Protopopescu C, Raffi F, et al: Satisfaction with care in HIVinfected patients treated with long-term follow-up antiretroviral therapy: the role of social vulnerability. AIDS Care 2012, 24:434-443.

12. Ghany MG, Strader DB, Thomas DL, Seff LB: Diagnosis, management and treatment of hepatitis C: un update. Hepatology 2009, 49:1335-1374.

13. WHO ASSIST Working Group: The Alcohol, Smoking and Substance Involvement Screening Test (ASSIST): development, reliability and feasibility. Addiction 2002, 97:1183-1194.

14. Curcio F, Di Martino F, Capraro C, et al: Together ... to take care: multidisciplinary management of hepatitis $C$ virus treatment in randomly selected drug users with chronic hepatitis. J Addict Med 2010, 4:223-232.

15. Ford N, Singh $\mathrm{K}$, Cooke GS, et al: Expanding access to treatment for hepatitis $C$ in resource-limited settings: lessons from HIV/AIDS. Clin Infect Dis 2012, 54:1465-1472.

16. Kieran J, Dillon A, Farrell G, et al: High uptake of hepatitis $C$ virus treatment in HIV/hepatitis $C$ virus co-infected patients attending an integrated HIV/hepatitis C virus clinic. Int J STD AIDS 2011, 22:571-576.

17. Parry J: HIV groups have much to teach hepatitis doctors about better diagnosis and treatment. BMJ 2012, 344:e1266.

18. Ingiliz P, Rockstroh JK: HIV-HCV co-infection facing HCV protease inhibitor licensing: implications for clinicians. Liver Int 2012, 32:1194-1199.

19. Cachay ER, Wyles DL, Goicoechea M, et al: Reliability and predictive validity of a hepatitis-related symptom inventory in HIV-infected individuals referred for hepatitis C treatment. AIDS Res Ther 2011, 8:e29.

20. Ge D, Fellay J, Thompson AJ, Simon JS, Shianna KV, Urban TJ, Heinzen EL, Qiu P, Bertelsen AH, Muir AJ, Sulkowski M, McHutchison JG, Goldstein DB: Genetic variation in IL28B predicts hepatitis C treatment-induced viral clearance. Nature 2009, 461:399-401.

21. Morse DS, Schiff M, Levit S, Cohen-Moreno R, Williams GC, Neumark Y: A pilot training program for a motivational enhancement approach to hepatitis $C$ virus treatment among individuals in Israeli methadone treatment centers. Subst Use Misuse 2012, 47:56-66.

22. Joshi D, O'Grady J, Dieterich D, Gazzard B, Agarwal K: Increasing burden of liver disease in patients with HIV infection. Lancet 2011, 377:1198-1209.

23. Moak ZSD, Osinusi A, Silk R, Kotb C, et al: Community engagement in a unique federal-local partnership: A model for hepatitits care and research [Abstract WEPE051]. In Program and abstracts of the19th International AIDS Conference July 22-27. Washington DC, USA. 2012.

24. Grint D, Peters L, Vogel M, Beniowski M, Pradier C, Battegay M, Jevtovic D, Soriano V, Lundgren J, Rockstroh J, Kirk O, Mocroft A: Temporal changes and regional differences in treatment uptake of hepatitis $C$ therapy in
EuroSIDA [Abstract 0243]. In Posters and abstracts of the Eleventh International Congress on Drug Therapy in HIV Infection, Glasgow. 2012.

25. Rourke SB, Sobota M, Tucker R, et al: Social determinants of health associated with hepatitis $C$ co-infection among people living with HIV: results from the Positive Spaces, Healthy Places study. Open Med 2011, 5:e120-e131.

26. McHutchison JG, Everson GT, Gordon SC, et al: Telaprevir with peginterferon and ribavirin for chronic HCV genotype 1 infection. N Engl J Med 2009, 360:1827-1838.

27. Poordad F, McCone J Jr, Bacon BR, et al: Boceprevir for untreated chronic HCV genotype 1 infection. N Engl J Med 2011, 364:1195-1206.

28. Lambert SM, Page AN, Wittmann J, et al: General practitioner attitudes to prescribing hepatitis $\mathrm{C}$ antiviral therapy in a community setting. Aust J Prim Health 2011, 17:282-287.

29. Hall CS, Charlebois ED, Hahn JA, Moss AR, Bangsberg DR: Hepatitis C virus infection in San Francisco's HIV-infected urban poor. J Gen Intern Med 2004, 19:357-365.

30. Poveda E, Vispo E, Barreiro P, de Mendoza C, Labarga P, Fernández-Montero $J V$, Martin-Carbonero L, Soriano V: Predicted effect of direct acting antivirals in the current HIV-HCV-coinfected population in Spain. Antivir Ther 2012, 17:571-575.

doi:10.1186/1742-6405-10-9

Cite this article as: Cachay et al.: Increasing Hepatitis $C$ treatment uptake among HIV-infected patients using an HIV primary care model. AIDS Research and Therapy 2013 10:9.

\section{Submit your next manuscript to BioMed Central and take full advantage of:}

- Convenient online submission

- Thorough peer review

- No space constraints or color figure charges

- Immediate publication on acceptance

- Inclusion in PubMed, CAS, Scopus and Google Scholar

- Research which is freely available for redistribution 